\title{
PERCEPTIONS OF MOTHERS AND CAREGIVERS REGARDING THE DETECTION AND TREATMENT OF SEVERELY MALNOURISHED CHILDREN IN KANCHELE, KALOMO DISTRICT, ZAMBIA
}

\author{
H. Khunga, MPH \\ University of the Western Cape \\ School of Public Health \\ K.J. Okop, MPH \\ University of the Western Cape \\ School of Public Health \\ T. Puoane, Dr PH \\ University of the Western Cape \\ School of Public Health \\ Corresponding author: tpuoane@uwc.ac.za
}

\begin{abstract}
Each year, malnutrition accounts for about 50 percent of the deaths of under-fives in developing countries. In Zambia, about 45 percent of children under the age of five exhibit stunted growth, mainly due to malnutrition. Early detection of cases by health workers and prompt health-seeking practices at household and community levels can improve the identification and management of malnutrition, and prevent unnecessary deaths. The study provides insights into the perceptions of mothers, caregivers, community members and community health workers regarding the detection, referral and health-seeking practices of malnourished children in Kalomo district of Zambia. This qualitative study explored perceptions and challenges of detection and prompt treatment of malnutrition (kwashiorkor and marasmus) in children under five years of age in the community. Focus group discussions using pictographs were conducted with purposely selected mothers and caregivers of children attending immunisation clinics in rural health centres in Zambia. In-depth interviews were also conducted with purposely selected grandparents, community health workers and nutrition advisors to validate the findings obtained from focus group discussions. Data were analysed using thematic analysis. Malnutrition, particularly marasmus, was linked to HIV infection. Barriers to seeking health care for severely malnourished children included beliefs about causes of malnutrition, failure to link malnutrition to poor feeding practices, distance to health care facilities and the lack of free feeding schemes for malnourished children. Mothers' decisions to seek care for malnourished children were influenced largely by grandparents. Increasing awareness about causes, signs and symptoms of malnutrition in this community is needed to improve detection and treatment of malnourished children.
\end{abstract}


Keywords: caregivers, community, malnutrition, perceptions, treatment

\section{INTRODUCTION AND BACKGROUND INFORMATION}

Malnutrition in children under five years of age is a global public health problem, especially in the developing world (Müller and Krawinkel, 2005:279). In 2012, it was estimated that 165 million children under five years of age were chronically malnourished or stunted, and more than 100 million were considered underweight (UNICEF, 2013a:24). Although global stunting and underweight prevalence declined from 34 percent to 27 percent and 27 percent to 22 percent respectively in Africa within a ten-year period (1990-2000), the number of stunted and underweight children is expected to increase respectively from 44 and 25 million to 48 and 31 million in 2020 (De Onis \& Blössne, 2003:521-522). Malnutrition is reported to contribute about 50 percent of all under-five deaths each year in developing countries (Rice, Sacco, Hyder \& Black, 2000:1207-1210). In Zambia, malnutrition in children is one of the main health challenges (CSO\&MoH, 2007); with stunting estimated in 45 percent of children under five in 2011 (UNICEF 2013b:8-9), contributing to the country's under-five mortality rate of over 202 deaths per 1000 births.

Severe acute malnutrition (SAM) in all its forms (viz kwashiorkor, marasmus and marasmic-kwashiorkor) has been reported to increase the risk of diseases and early death (De Onis \& Blössne, 2003:518). In addition, there is also strong evidence to suggest that malnutrition is associated with delayed mental development, poor school performance, and reduced intellectual capacity (De Onis, 2001:72). A community-level strategy that incorporates effective identification, referral, and timely management of malnourished children has been recommended as facets of efficient care for children with severe or moderate malnutrition (World Health Organisation, 2011).

In Zambia, a referral system that facilitates the identification of children with childhood illnesses, including malnutrition, at the community level using community health workers (CHWs), is being implemented. In this programme, children who are underweight for their age are identified from the community by using mid-upper arm circumference measurements and are referred to the nearest rural health centre (RHC) or primary health centre $(\mathrm{PHC})$ for treatment. Children that cannot be treated at primary care level due to complications are referred to a district hospital.

\section{STATEMENT OF THE RESEARCH PROBLEM}

Increasing deaths among severely malnourished children under the age of five have been reported in rural Zambia (Bachmann, 2010:2226) and in many sub-Saharan African countries (Irena, Mwambazi \& Mulenga, 2011:100). In 2010, it was documented that mild to severe malnutrition of under-fives increased from 32 percent to 52 percent within a year in the Kalomo-Kanchele community. Although all the malnourished cases 
detected by CHWs in this community were referred to the nearby RHCs, about 60 percent did not get to the health centres for treatment (CFAARM, 2010:1-3). Those who went to the RHCs arrived too late, and many of them died before or during admission. This has resulted in high mortality rates for the malnutrition wards (National Food and Nutrition Commission, 2006).

Early detection of cases and prompt care-seeking practices of caregivers have been shown to improve the management of malnourished children and prevent unnecessary deaths (UNICEF, 2013b:5-6). However, only a few studies have explored the factors that affect the management of SAM at the various levels in the continuum of care in Zambia. Information on perceptions of mothers, caregivers, community leaders, CHWs and PHC staff on the detection, referral and management of severe malnutrition in children under the age of five will inform the development of cost-effective interventions that can reduce unnecessary deaths due to malnutrition in rural Zambia.

\section{PURPOSE OF THE STUDY}

The main purpose of this study was to explore the perceptions of mothers and caregivers regarding severely malnourished children under the age of five.

\section{Definitions of keywords/concepts}

- A mother in this paper refers to a biological mother of an under-five child, unless stated otherwise.

- A caregiver in this study refers to a woman other than the child's mother, grandparent or guardian, CHW or PHC-based nutrition counsellor who takes care of an underfive child by providing food and basic needs or counselling services for at least one year.

- Community health workers (CHWs) are first-level community-based health care volunteers who support referral and treatment at community level.

- Community describes the geographical area within which the study is set.

- Malnutrition in this paper refers to multiple nutrients deficiencies presented in any of its three forms viz kwashiorkor, marasmus and marasmic-kwashiorkor.

- Treatment is the facility-based management of malnourished children, except where stated otherwise.

- Perceptions refer to inert ideas in the minds of people regarding a particular issue (eg malnutrition). 


\section{RESEARCH METHODOLOGY}

\section{Study design}

A descriptive exploratory design using qualitative data collection methods was used in this study.

\section{Study setting}

The study was undertaken in the Kanchele community in Kalomo, a rural district with a total population of approximately 169503 (Central Statistical Office, 2003) located about $400 \mathrm{~km}$ from the Zambian capital city, Lusaka. The district is prone to droughts, floods, and food security problems.

\section{Study population and sampling procedure}

The study target population was mothers and caregivers including grandmothers, community members and leaders (men and women) with children under the age of five in their households, as well as CHWs and nutrition counsellors who had lived or worked in Kalomo villages for at least a year. Two out of the list of 12 RHCs in Kalomo district from where most of the severely malnourished children arrived at the referral (district) hospital in a very critical condition or with complications, were purposively selected for the study. Mothers and caregivers of under-five children were selected during their routine immunisation clinic visits in both health centres to participate in the group discussions. Community members were selected by the village headman during 'muswangano' (a community meeting). Involvement of community members from most sections of communities was ensured by the research team and the village headman.

\section{Data collection}

Data were collected between May and June 2012 after the approval of the study by the University of the Western Cape Ethics Committee, and after receiving permission from Kalomo district, Zambia for the implementation of the research. Six focus group discussions were conducted with mothers, caregivers, CHWs and community members. Discussions were undertaken at designated venues within the primary health care clinic, and at community town halls for community member groups. Only $\mathrm{CHWs}$ who were currently providing care to mothers of under-fives were included in the discussions. Each focus group discussion session began with a display of two pictures: one of a child with marasmus (Pic1) and the other of a child with kwashiorkor (Pic2). The research team asked the participants if they had seen children in their community who looked like those in the pictures and went on to discuss the perceived causes and treatment 
of these conditions. Challenges experienced in identifying and treating malnourished children were also elucidated.

Six in-depth interviews were also conducted with a nutrition counsellor, CHWs and community members (see table 1) to validate the findings obtained from focus group discussions. All discussions and interviews were conducted in the local language, Tonga. Discussions were recorded and non-verbal communication cues like gestures were written down by a note taker. Discussions continued until the issues discussed were seemingly exhausted.

\section{Trustworthiness of the study}

Two research assistants experienced in qualitative research facilitated the focus group discussions and conducted the interviews. At the completion of the data collection process, information was summarised and presented back to the participants to ensure that it reflected what they meant. To ensure rigour and validity, all transcripts were reviewed by one researcher - after listening and cross-checking most sections of the transcripts with the recorded interviews.

\section{Ethical considerations}

Approval for the study was obtained from the research ethics committee of the University of the Western Cape. Permission to conduct the study was obtained from the local political leadership in Kalomo district. The study was properly explained to participants with the aid of an information sheet written in participants' local dialect. A consent form was also completed by every participant who gave verbal consent to participate in the study. All information obtained during the study was kept strictly confidential. No expected harm was implied to the study participants. Preliminary findings of this study were shared with community leaders and members (men and women) during a community-level meeting.

\section{ANALYSIS AND FINDINGS}

A thematic analysis approach was used. First, both group discussions and in-depth interviews transcripts were hand-coded and grouped according to emerging themes. Nine broad themes were identified and later merged into five relevant themes based on the focus of the research. Internal coherence within and distinctions between themes were ensured through a logically aligned and theory-driven coding process. Two researchers independently reorganised the themes and made inferences based on the findings. The demographic characteristics of study participants are displayed in table 1 . 
Table 1: Participants' demographic characteristics

\begin{tabular}{|l|l|l|l|}
\hline Participants & $\begin{array}{l}\text { Number of } \\
\text { participants }\end{array}$ & $\begin{array}{l}\text { Age range } \\
\text { (years) }\end{array}$ & $\begin{array}{l}\text { No of } \\
\text { sessions }\end{array}$ \\
\hline Focus discussions & 12 & $17-43$ & 2 \\
\hline Mothers & 10 & $35-47$ & 1 \\
\hline Caregivers & 10 & $30-50$ & 1 \\
\hline Community members (women) a & 11 & $38-60$ & 1 \\
\hline Community members (men) ${ }^{b}$ & 8 & $26-40$ & 1 \\
\hline CHWs and nutrition counsellors & \multicolumn{2}{l}{} \\
\hline In-depth interviews & \multicolumn{1}{l|}{} \\
\hline CHWs & 1 & $30-47$ & 2 \\
\hline Nutrition counsellor & 1 & 35 & 2 \\
\hline Community members (men) & 1 & 45 and 60 & 2 \\
\hline
\end{tabular}

${ }^{a}$ Women leaders, women church leaders; ${ }^{b}$ community head, area councillors, church leaders, section leaders;

c female nutrition group leaders

The main themes identified from the discussions and interviews were: beliefs about malnutrition, perceived causes of malnutrition, challenges around the detection of malnourished children, referral and care of malnourished children, and care-seeking actions for a malnourished child. These are discussed in the following section and illustrated with some quotes from the participants.

\section{Participants' beliefs about malnutrition}

Different beliefs about malnutrition were revealed by participants. Some mothers and community members believed that a child with marasmus had HIV/AIDS, and this was said to increase stigma for both the mother and the child. A mother attested to this: 'The child [in Pic1] is very thin and looks like a child who has HIV or AIDS'.

Another mother who also believed that the child in Pic1 had HIV/AIDS, affirmed the perceived HIV stigma as follows: 'If he [the child] was my baby, no one would ever see me outside with him because they would think I have HIV'.

Malnutrition was also associated with 'bad air' in the environment where the child was raised. In such a case, the child would be relocated to another village that was approved by the grandparents or traditional healers. One caregiver stated: "this child swells because of bad air in that environment [where he/she lives], and should be moved to a different village'. 


\section{Perceived causes of malnutrition}

Mothers, caregivers, community members and $\mathrm{CHWs}$ had varying perceptions about the causes of malnutrition. Although many women had information about the causes of malnutrition from their interactions with some health care workers, most women (more than half) participating in the discussion linked kwashiorkor and marasmus to the child's father's immoral behaviour (or promiscuity). Some men and women in all groups interviewed also believed that kwashiorkor was a form of bewitchment. Two common opinions among the participants (mother and caregiver groups) were:

'This type of sickness [referring to Pic2] is definitely a sign of bewitchment'. 'This child (referring to Pic1) is suffering from 'masoto' [wasting], ...a sickness resulting from the child's father sleeping around and coming home to hold a baby without using traditional medicine to cleanse himself'.

Community leaders, PHC-based nutrition counsellors, and CHWs readily admitted that mothers' poor infant-feeding practices (that is, feeding a child with junk, left-over or contaminated foods) and complementary feeding were associated with malnutrition. However, most mothers (15 out of 24) did not consider these as potential causes of malnutrition in children. In addition, participants associated poverty, diarrhoea and breastfeeding a child during pregnancy with a form of malnutrition.

\section{Challenges with detection, referral, and care of malnourished children}

The challenges with detection, referral and actual care-seeking for mothers and caregivers were identified at the community, household and health-facility levels. For example, CHWs indicated that they walked long distances around the villages for growth monitoring and follow-up activities, and that some parents did not comply with their counselling and referral advice. Some mothers even accused CHWs of being responsible for their child's illness. CHWs were, however, optimistic that, if supported by the facility health-care workers (such as nurses and social workers), parents might adhere to their advice. One of the CHWs commented:

Some of us try to talk to the parents of the malnourished child on how to feed the child, but some parents sooner or later start pointing at you [the CHW] as the one bewitching the child. It would be much easier if the people from the health centre told the parents about the child's condition - they would easily follow [adhere to] what the health centre staff said.

On the other hand, mothers and caregivers had some difficulties in supporting CHWs in the detection and treatment of malnourished children. Some mothers and caregivers refused to take a child for treatment even after referral advice was given, fearing hospital admission and child death upon admission. Participants commonly stated that distances 
to the health facilities, poor road networks and the lack of access to health-care providers in the community were barriers to seeking care for a malnourished, sick child.

At health facility level, inadequate personnel and lack of functioning anthropometric equipment such as mid-upper arm circumference tape, height metre measures and weighing scales were reported to make the screening of children referred to the centre difficult. In addition, parents' refusal to bring their children for scheduled growth monitoring hindered the identification and treatment of cases. Also, the lack of feedback between health facilities and households (parents) through CHWs left families uninformed about referrals and treatment outcomes. Moreover, community members expressed a lack of confidence in the services of some CHWs, perceiving those as a 'last resort' treatment option. They also felt that CHWs had no certificates to prove that they had enough knowledge about health care. This situation was known to community leaders. A community leader commented:

As leaders, at times we try to get the parents to take the child to see a CHW. However, some parents feel that a CHW can't tell them anything different to what they already know.... They would instead want to hear and believe what someone [else] from outside the village would tell them.

\section{Care-seeking actions for a malnourished child}

Mothers and caregivers reported taking a number of actions when they discovered that a child was malnourished, such as taking the child to a traditional healer. Many believed that only a traditional healer can appease for the father's wrongdoing (promiscuity), and/ or remove bewitchment from the child. Some parents would also take a malnourished child to a RHC, usually if the child had diarrhoea. Other parents gave children medicine purchased from local medicine stores (ie tutemba). A young mother with an infant commented and gave two reasons for seeking care from traditional healers: 'Parents often sought help from the traditional healers [nganga] ... to get traditional medicine to cure the child and to prevent bad spirits from attacking the child again'.

On the whole, mothers and caregivers highlighted some other specific challenges at household, community and clinic levels that posed hindrances to them seeking prompt care for a severely malnourished under-five child. These included fathers' monopoly over decision-making around child care, having many children in a household, the cost of taking care of the child and the siblings in hospital, fear of hospital admission and long waiting times on arrival, and lack of free food at the hospital during admission.

\section{DISCUSSION}

This study revealed a lack of knowledge about the causes of malnutrition among mothers, caregivers and community members. It also identified commonly held 
perceptions about malnutrition and some challenges regarding care for the malnourished children among the study participants. Mothers and caregivers perceived a 'thin' child as HIV-infected, and HIV/AIDS stigma was seemingly high among the participants. These findings confirmed that of Matoti-Mvalo and Puoane $(2011: 40,42)$ in which respondents suspected thin persons (in silhouettes) of being infected with HIV. Although participants also alluded to immediate causes (inadequate dietary intake and disease) as an underlying cause of child under-nutrition, HIV/AIDS was emphasised, probably due to its rapid weight loss and wasting effects on children. This belief may be due to the fact that the number of people with HIV/AIDS increases in communities as people become increasingly aware of the symptoms of this condition and now regard anyone who has experienced weight loss as being HIV infected.

Poor practices such as inadequate dietary intake and feeding children with unbalanced diet and junk foods were common in this study, as was the case in previous studies undertaken in rural (Bachmann, 2010) and urban (Irena et al, 2011:100-104) Zambian communities, as well as rural South Africa (Puoane et al, 2001:137,139). Inadequate feeding and poor feeding practices have been increasingly associated with SAM and deaths of under-fives (Puoane et al, 2001; Kumar Goel, Mittal \& Misra, 2006:417), especially when coupled with diarrhoea or infections (Irena et al, 2011:100-103). Similar findings were also reported by Aahtera et al (2001:328) who also associate early childhood malnutrition in a rural Malawian community with unusual feeding practices among mothers with low socioeconomic status.

Interestingly, in the current study, poor feeding practices were recognised by the community leaders, $\mathrm{CHWs}$ and nutrition counsellors as being what put children at risk of malnutrition. However, some mothers and caregivers associated malnutrition with the child's father's promiscuity and witchcraft rather than with poor feeding practices. Ignorance or lack of awareness of the potential risk of inappropriate feeding practices could explain the reason for the persisting problem of SAM in this community.

The study also revealed the enormous challenges regarding the detection of severely malnourished under-fives in the community, and management of such children at PHC. The challenges of a shortage of staff and dysfunctional equipment to screen children at PHCs were critical and hindered treatment of the cases referred. This resulted in children being turned back and asked to return on another day. Inadequate manpower and infrastructure have been identified as affecting effective management of SAM among children in rural and urban communities of Zambia (Charlton, Kawana \& Hendricks, 2009:36-37) as well as in South Africa (Puoane et al, 2001:137). Distance to health facilities and bad roads were reported by study participants as other challenges that prevented mothers from taking children to hospitals. In addition, some mothers narrating their previous experiences with health facility care for a malnourished child alleged that PHC nurses often blame them for their children's illness and this sometimes 
discouraged them from taking their children to clinics when they were sick. Similar findings were also reported by Puoane Sanders, Ashworth and Ngumbela (2006:73, 75) in a study undertaken in South African locations with increasing child mortality due to malnutrition.

Moreover, overall hospital use in rural Zambia is low - 29.7 percent - and this has been attributed to the aforementioned problems, as well as lack of maternal and child healthfriendly services (Hazemba \& Siziya, 2008:53-55). Similar findings were reported in a recent study (Pandian, Suresh, Desikachari \& Padmanaban, 2013:330-331) undertaken in rural Indian communities, in which poor use of hospitals in rural communities was associated with a lack of innovative and friendly health-care services.

Poor access to PHCs, the stigma of caring for a 'thin' child in hospital, and fear of hospital admission (due to previous experience of long waiting times), were identified in this study as some of the reasons for the poor management of severe malnourishment in under-fives. While mothers' and caregivers' confidence in facility-based care for malnourished children could be improved by appropriate feedback processes between health facilities, households and communities, the current study found there was a lack of communication and feedback of outcomes of referrals to the community.

In many countries marginalised population groups rely on the services provided by CHWs. However, in this study the services rendered by CHWs were perceived as a 'last-resort' treatment option. This perception is suspected to be largely due to mothers' or caregivers' expectations of CHWs to provide drugs (such as antimalarial medication and oral rehydration therapy) and some care for a sick child at home, not being met. CHWs most often referred identified cases, but had very limited or no medical supplies for essential home-based care. Training and equipping CHWs with approved drugs (such as antimalarial, anthelminthic, oral rehydration therapy and ready-to-use therapeutic food) to meet the needs of SAM at home, should be explored within the community health-care re-engineering strategy. Such an exploration could draw on a recent study in which the acceptability of ready-to-use therapeutic food in Zambian communities was tested (Owino, Irena, Dibari \& Collins, 2014:126-129).

Relying on traditional healing was a common practice in the study community. Traditional healers were often preferred to health facility care as they were considered to be easily accessible, cheap, and more accommodating of mothers accompanied by siblings of the sick child, unlike the PHCs. The general belief in culturally perceived causes of malnutrition and other child illnesses among community members was obviously the main reason for this preference. A study conducted in Malawi indicates that traditional beliefs about causes of malaria negatively affected the diagnosis and early treatment of sick children (Chibwana, Mathanga, Chinkhumba \& Campbell, 2009). 
Some of the mothers did not comply with CHWs' referral advice for either child growth monitoring or treatment at a clinic. This is in contrast to the findings of an earlier study conducted in Lusaka which showed that mothers or caregivers were very willing to adhere to advice to seek health care for their children (Mason et al, 2010:209). It was obvious from the analysis of maternal challenges that $\mathrm{CHWs}$ ' influence on caregivers and parents was largely dependent on (1) trust in CHWs' services, (2) CHWs' healthcare skills and (3) CHWs' social marketability in competing with the local traditions and superstitions identified in the study.

In general, the identification and actual seeking of facility-based treatment for a malnourished child were dependent on many related issues which included the home, the community, up to the PHC. At home, for instance, most mothers or caregivers had no right to make decisions concerning a child's health care. Mothers could take a sick child to a health centre (if the child's father or grandparents approved), but were also obligated to take care of that child's siblings. In the community, grandparents emphasised and enforced traditional healing, while mothers faced some form of nagging at PHCs. These phenomena could explain a sick child's mother's non-acceptance of and noncompliance with referral recommendations.

Lastly, facility-based SAM treatment approaches have been greatly limiting in their coverage and impact in most Zambian communities. Interestingly, recent evidence suggests that a large number of children can be treated without admission to a primary health facility (World Health Organisation, 2011). Community-based treatment of SAM should therefore be considered most appropriate for the prevention and management of malnutrition, especially in rural communities, as it has been shown to be more costeffective compared to other priority health interventions (Bachmann, 2010:605-607, $610)$.

\section{CONCLUSIONS}

This study revealed the lack of knowledge about causes, signs, symptoms, and treatment of malnourished children among mothers or caregivers and community members in Kalomo district in Zambia. A strong belief in traditional healers, linking malnutrition to traditional beliefs, poor reception at health-care facilities, as well as a lack of confidence in the services offered by CHWs are some of the barriers to the prompt management of malnourished children.

\section{RECOMMENDATIONS}

Community-based health education and promotion that integrates continuous malnutrition-focused training for mothers, community members and CHWs could improve detection and treatment of malnourished children in a setting where traditional 
healing is highly esteemed. Such intervention that incorporates practical learning on how to prepare ready-to-use therapeutic food with locally available ingredients - which has been successful in rural Zambia (Owino et al, 2014:126) - should be implemented. Additionally, grandparents can be trained as mother or father-mentors for child health care to provide community-level support for the management of SAM. This option facilitated universal access to peer support for women in prevention of mother-to-child transmission services for over two million women and children and increased retention in remote communities of Zimbabwe (Shroufi et al, 2013:2-5) and South Africa (Youngleson et al, 2010:1-4), among other things. Furthermore, the Zambian Ministry of Health should explore the possibility of implementing community-led interventions to improve the identification, referral, and treatment of severely malnourished children and should consider the training and adequate involvement of PHC nurses, CHWs and community leaders as essential.

\section{LIMITATIONS OF THE STUDY}

The communities and RHCs were purposively selected. Although it might not be possible to generalise these findings to the entire Kalomo district, they do, however, yield important information required for the planning and implementation of communitybased interventions for the prevention of severe malnutrition in children under the age of five, especially in Zambia. Furthermore, the views of participants who attended immunisation clinics may only represent views of mothers and caregivers who had used PHC services at the time of the study. However, the inclusion of key stakeholders in the community added to the views of the community that we studied.

\section{ACKNOWLEDGEMENTS}

We acknowledged the community leaders, Kanchele health centres and staff, CHWs, and members of Kanchele communities who were part of the study.

\section{REFERENCES}

Aahtera, M., Kulmala, T., Hietanen, A., Ndekha, M., Cullinan, T., Salin, M.L. \& Ashorn, P. 2001. Breastfeeding and complementary feeding practices in rural Malawi. Acta Paediatrica, $90: 328-332$.

Bachmann, M.O. 2010. Cost-effectiveness of community-based treatment of severe acute malnutrition in children. Expert Review of Pharmacoeconomics and Outcomes Research, 10(5):605-612.

Central Statistical Office \& the Ministry of Health. 2007. Zambia demographic and health survey. http://countryoffice.unfpa.org/zambia/drive/2007_zdhs_final_report.pdf (Accessed 30 January 2015). 
Central Statistical Office, Zambia. 2003. Zambia Demographic and Health Survey 2001-2002. Calverton, MD: Central Statistical Office, Central Board of Health.

CFAARM see Consortium of Food, Agriculture, Aids, Resiliency and Markets.

Charlton, K., Kawana, B. \& Hendricks, M. 2009. An assessment of the effectiveness of growth monitoring and promotion practices in the Lusaka district of Zambia. Nutrition, 25(10):10351046.

Chibwana, A., Mathanga, D.P., Chinkhumba, J. \& Campbell, C. 2009. Socio-cultural predictors of health-seeking behaviour for febrile under-five children in Mwanza-Neno district, Malawi. Malaria Journal, 8:219. http://www.malariajournal.com/content/8/1/219 (Accessed 5 April 2014).

Consortium of Food, Agriculture, Aids, Resiliency and Markets. 2010. Semi-annual report to USAID. Lusaka: Unpublished report.

CSO\&MoH see Central Statistical Office \& the Ministry of Health.

De Onis, M. 2001. Child growth and development. In: R.D. Semba \& M.W. Bloem (eds). Nutrition and Health in Developing Countries. Totowa, NJ: Humana Press, 71-91.

De Onis, M .\& Blössne, M. 2003. The World Health Organization Global Database on Child Growth and Malnutrition: methodology and applications. Journal of Epidemiology, 32:518-526.

Hazemba, A. \& Siziya, S. 2008. Choice of place for childbirth: prevalence and correlates of utilization of health facilities in Chongwe district, Zambia. Medical Journal of Zambia, 35:5357.

Irena, A.H., Mwambazi, M. \& Mulenga, V. 2011. Diarrhoea is a major killer of children with severe acute malnutrition admitted to inpatient set-up in Lusaka, Zambia. Nutrition Journal, $11: 100-110$.

Kumar, D., Goel, N.K., Mittal, P.C. \& Misra, P. 2006. Influence of infant-feeding practices on nutritional status of under-five children. The Indian Journal of Paediatrics, 73(5):417-421.

Mason, J.B., Chotard, S., Bailes, A., Mebrahtu, S. \& Hailey, P. 2010. Impact of drought and HIV on child nutrition in Eastern and Southern Africa. Food and Nutrition Bulletin, 31(3 Suppl):209-218.

Matoti-Mvalo, T. \& Puoane, T. 2011. Perceptions of body size and its association with HIV/AIDS. South African Journal of Clinical nutrition, 24(1):40-45.

Müller, O. \& Krawinkel, M. 2005. Malnutrition and health in developing countries. Canadian Medical Association Journal, 173(3):279-286.

National Food and Nutrition Commission. 2006. Annual report. Lusaka: National Food and Nutrition Commission.

Owino, V.O., Irena, A.H., Dibari, F. \& Collins, S. 2014. Development and acceptability of a novel milk-free soybean-maize-sorghum ready-to-use therapeutic food (SMS-RUTF) based on industrial extrusion cooking process. Maternal and Child Nutrition, 10(1):126-134.

Pandian, J., Suresh, S., Desikachari, B.R. \& Padmanaban, P. 2013. Increased utilization of primary health care centers for birthing care in Tamil Nadu, India: a visible impact of policies, initiatives, and innovations. Journal of Family Medicine and Primary Care, 2:329-333.

Puoane, T., Sanders, D., Ashworth, A. \& Ngumbela, M. 2006 Training nurses to save lives of malnourished children. Curationis, 29(1):73-78.

Puoane, T., Sanders, D., Chopra, M., Ashworth, A., Strasser, S., McCoy, D., Zulu, B., Matinise, N. \& Mdingazwe, N. 2001. Evaluation of clinical management of severely malnourished children: a study of two rural district hospitals. South African Medical Journal, 91:137-141. 
Rice, A., Sacco, L., Hyder, A. \& Black, R.E. 2000. Malnutrition as an underlying cause of childhood deaths associated with infectious diseases in developing countries. Bulletin of the World Health Organization, 78(10): 1207-1221.

Shroufi, A., Mafara, E., Saint-Sauveur, J.F., Taziwa, F. \& Vinoles, M.C. 2013. Mother to Mother (M2M) Peer Support for Women in Prevention of Mother to Child Transmission (PMTCT) programmes: a qualitative study. PLOS ONE, 8(6). http://journals.plos.org/plosone/ article?id=10.1371/journal. pone.0064717 (Accessed 30 January 2015).

UNICEF see United Nations International Children's Emergency Fund.

United Nations International Children's Emergency Fund. 2013a. State of the world's children 2013: children with disabilities. http://www.unicef.org/sowc2013/files/SWCR2013_ENG_ Lo_res_24_Apr_2013.pdf (Accessed 3 April 2014).

United Nations International Children's Emergency Fund. 2013b. Improving child nutrition: the achievable imperatives for global progress. http://www.unicef.org/media/files/nutrition report_2013.pdf (Accessed 7 January 2014).

World Health Organisation. 2011. Community-based management of severe acute malnutrition: a joint statement. http://www.who.int/nutrition/publications/ severemalnutrition/9789280641479/en/index.html (Accessed 3 January 2014).

Youngleson, M., Nkurunziza, P., Jennings, K., Arendse, J., Mate, K. \& Barker, P. 2010. Improving mother to child HIV transmission programme through health system redesign: quality improvement, protocol adjustment and resource addition. PLOS ONE, 5(11). 